\title{
Discussions
}

\section{ZAHAR ON MACH, EINSTEIN AND MODERN SCIENCE}

I In his [1977] note (numbers in brackets will from now on mean pages of this note) Elie Zahar states

(A) that Einstein, when introducing special relativity, violated 'cardinal' principles of Mach's philosophy (205);

$(B)$ that without the violation 'the special theory of relativity would never have seen the light of the day' (195); and he infers

$(C)$ that Mach's philosophy 'was largely irrelevant to the development of modern physics' (195).

Now the fact that Einstein violated some 'principles' of Mach's philosophy does not show that his ideas were independent of other principles of that philosophy; nor does it show that the philosophy did not influence other parts of modern physics, such as the quantum theory: Zahar's arguments do not establish $C$.

2 They also fail to establish $A$.

Zahar mentions four conflicts between Mach and Einstein's ideas and procedures. They are $(A I)$ : relativity 'is a causal theory in the traditional sense of the word' (203) i.e. a theory involving an assymmetry while Mach's functional approach eliminates all assymmetries (202). ( $A 2)$ Einstein's definition of simultaneity violates 'one of Mach's cardinal methodological principles' (205) and it is also 'radically different' (203) from Mach's definition of mass. ( $\left.A_{3}\right)$ the special theory of relativity uses inertial frames which, being unobservable, are anathema to Mach. 'It is therefore small wonder' writes Zahar on this point 'that Mach should have disowned relativity' (206). Inertial frames are also needed to make sense of general covariance hence Mach, when arguing for general covariance 'was violating a tenet of his own branch of positivism' (212). $\left(A_{4}\right)$ for Einstein (a) 'laws have an ontological status over and above the observables which they correlate with one another' (212) and (b) they must have such special status, for otherwise the arguments for general covariance again fail to make sense.

3 But Mach, far from treating inertial systems as metaphysical monsters examined their properties and watched with interest and approval the attempt to make them a basis for astronomical measurements. He regards Corollary V of Newton's Principia ${ }^{1}$ 'as providing the only practically useful (and most likely approximate) inertial system ${ }^{2}$ and he presents L. Lange's 'attractive idea' concerning the definition of such systems. ${ }^{3}$ The definition, Mach remarks, separates

${ }^{1}$ Cajori (ed.) [1962], $20 \mathrm{f.} \quad{ }^{2}$ Mach [1933].

${ }^{3}$ Mach [1 1933], p. 233. Mach mentions some technical difficulties of Lange's definition, but he nowhere regards it as metaphysical. 


\section{Paul Feyerabend}

the 'conventional' and the empirical elements of the law of inertia which consists in a 'restriction of the kinematically possible manifold'. Mach also describes Seeliger's research concerning the relation between inertial systems and the 'empirical coordinate systems actually in use in astronomy'. The attempts to establish 'ephemeris time' and a fundamental reference system ${ }^{1}$ which are attempts to make inertial systems the basis of astronomical observations are well known to him and are regarded by him as important empirical investigations: Mach's aversion to relativity has no connection with the occurrence of inertial systems in it.

$4 A_{4} a$ is also incorrect. In his essay 'Physics and Reality" which criticises the quantum theory for its 'incomplete representation of real things', 'Einstein explains what he means by 'real existence':

Out of the multitude of our sense experience we take, mentally and arbitrarily, certain repeatedly occurring complexes of sense impressions ... and correlate to them a concept-the concept of the bodily object. Considered logically this concept is not identical with the totality of sense impressions referred to; but it is a free creation of the human (or animal) mind. On the other hand this concept owes its meaning and its justification exclusively to the totality of the sense impressions which we associate with it.

The second step is to be found in the fact that, in our thinking (which determines our expectations), we attribute to this concept of a bodily object a significance which is to a high degree independent of the sense impressions which originally gave rise to it. This is what we mean when we attribute to the bodily object a 'real existence'. 4

This passage is pure $M a h^{\downarrow}$ as can be seen from what Mach says about concepts in Erkenntnis und Irrtum': according to Einstein the issue in quantum theory is not an 'ontological' issue (212) whatever that means-it is an issue over different modes of 'arbitrarily' ordering sense data. '

${ }^{1} C f$. the explanations given in the Explanatory Supplement to the Astronomical Ephemeris and Nautical Almanac, London, 196r.

Einstein [ 1936 ] p. 221 ; reprinted in [1954], 290 ff. I shall quote from the latter source.

p. $325 \mathrm{f}$. Italics in the original.

p. 291 .

'Except that Mach's account is more realistic than Einstein's: Mach ascribes to a natural development what Einstein regards as a 'free creation of the human (or animal) mind'. For Einstein concepts are freely at our disposal. For Mach their formation obeys psychological laws.

- Both steps are explained already in Mach's earlier writings, for example in his [1896], pp. 207, 213 (first presented at a meeting of the Vienna Academy in 1882 ).

7 The same applies to Boltzmann's defence of atomism. 'Hertz made it very clear to physicists' Boltzmann said in I899 (See his [1905], p. 215) 'what philosophers most likely have said long ago, that a theory cannot be an objective thing, in agreement with nature, but can at most be a mental picture of phenomena, being related to them like the sign to the thing signified'. (Hertz had used the term Scheinbild $\longrightarrow$ phantom picture). Boltzmann, accordingly, regarded theories such as the atomic theory as 'mental pictures' (p. 142); his defence of atomism was not an 'ontological' argument, but an argument 
Confronted with Machian utterances by scientists Zahar speaks (more than once) of 'paying lip service to Machian positivism' (195) and he adds that scientists often do one thing and say another (197): obviously it needs a philosopher to find out what is really going on. But the above quotation cannot be explained away in this simple fashion. It is part of a long article on the situation in physics; it prepares a criticism of the quantum theory; it does not belong to Einstein's early period where some 'lip service' to Mach might have occurred (though it is not at all clear why Einstein should pay 'lip service' to any philosophy) but to the 'reactionary' part of Einstein's life when to outsiders he more than ever seemed to be an 'old fashioned realist' (195). The quotation shows that he was 'old fashioned' in the sense of Mach: his objections are conceptual, not 'ontological'. And the article as a whole shows that the saying-doing dichotomy is anything but realistic in Einstein's case: it is very implausible to assume that Einstein, when directing attention to epistemological matters closely connected with the physical research he was engaged in should have failed to know what he was talking about. ${ }^{1}$ A look at $A \not b$ shows that he certainly did not on the matter at issue.

5 Zahar says that arguments about covariance involve the behaviour of laws in different reference systems and therefore assume 'that laws and their form possess an objective status' (212); they also assume coordinate systems which are forbidden by Mach and run counter to the principle, allegedly defended by Mach, that the simplest formulation of a law is the best: 'there is no good reason, from a Machian viewpoint, why the choice of a certain coordinate system should not prove more convenient than another' (212). The last point is of course true and this is why particular problems such as the relativistic advance of the perihelion of Mercury are calculated in special reference systems (Schwarzschild's calculation). But if the purpose is to get laws connecting the special cases then 'physics, for reasons of economy, often gives us equations between functions of the primary variables and not equations between the primary variables themselves' " and the task is then to make these equations as simple as possible: Zahar has a rather simpleminded view of Mach's conception of economy. But does not

concerning the superiority of some pictures over others and he emphasised that arguments of this kind were perfectly in agreement with Mach's general philosophy. Mach, on the other hand ('whose relevant writings greatly contributed to the clarification of my own views'-op.cit., p. $142, n$. I) had no objections to even the most outlandish ones of Maxwell's models and ascribed to them 'Maxwell's extraordinary success': Mach [1917] (first published in 1905), p. $229 \mathrm{f}$. These and other matters are explained in detail in M. S. Curd's thesis, Ludwig Boltzmann's Philosophy of Science, Pittsburgh, 1978 , where the 'hagiographic' account of the 'realist' Boltzmann's battle against shortsighted positivists such as Mach and Ostwald is laid to rest once and for all.

${ }^{1}$ Einstein is the last of the late nineteenth century scientist-philosophers who like Maxwell, Hertz, Mach, Boltzmann and Duhem designed philosophies for advancing science and used (corrected) these philosophies in their research. Today philosophers are outsiders with correspondingly unrealistic views of history and scientific method. Zahar wants to convince us that these outsiders have a better view of science than the most outstanding scientists. His article tells otherwise.

2 'Die oekonomische Natur der Physikalischen Forschung' quoted after Mach [1896], p. 228. 


\section{Paul Feyerabend}

the formation of functions of laws assume that laws have an 'objective status'? Yes-but not in Zahar's sense: talking about blueprints assumes that blueprints are 'objective' but not in the sense that they have an 'ontological status over and above' the things they are blueprints of. The 'objectivity' of a blueprint, however, can be easily explained in Einstein's (i.e. Mach's) manner, by giving an account of the way in which its elements hang together. Reference systems, finally, are elementary for a Machian (see the refutation of $A_{3}$ above). This concludes the refutation of $A_{4}$.

6 There remains $A 2$. The answer is here that Zahar has interpreted a difference between definitions (definition of mass on the one side, definition of simultaneity on the other) as a difference between philosophies (Mach's and Einstein's). But Mach, far from subjecting definitions to rules $1-3$ (202f) distinguishes various types of definitions, purely 'nominal stipulative' (207) definitions included. For example, he considers the following definitions of a time metric: (a) $t$ is proportional to the angle of the earth with respect to some inertial system; (b) $t$ is proportional to the logarithm of this angle, and he comments on the arbitrary and rival-hypotheses-compatible (207) nature of the stipulations. ${ }^{1}$ Einstein's definition of simultaneity falls into this category and is therefore anything but a 'viola[tion] . . . of Mach's cardinal methodological principle' (205). Nor did Mach ever subject definitions to condition 2 (203). Quite the contrary-in his definition of mass he explicitly states the dependence of the definition on 'the existence of a special, acceleration-determining quality of

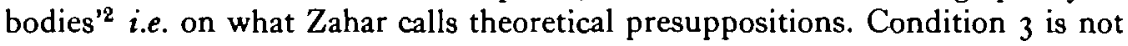
Machian either. For although Mach objects to what one might call direct circularity (explicit definitions which contain the thing to be defined) he is well aware of the fact that concepts, being dependent on each other in many ways, cannot always be explained in isolation. Zahar's condition I, however, (20I) can be refuted at once: 'Which concepts we form' writes Mach, 'how we delimit them with respect to each other-all that can be decided only by the needs of practice, or of science': Mach is much more liberal than modern philosophers of science and his 'cardinal methodological principle' (205) is nothing but a chimaera in Zahar's head.

$A I$, finally, overlooks that Mach paid great attention to unidirectional processes $^{44}$ and occasionally regarded them as fundamental: not all connections are symmetrical and those which are 'are secondary, not basic'. 5 Zahar connects Mach's alleged failure to account for assymmetry to his 'conceptual-as opposed to the propositional-approach' (202). He overlooks that Mach's concepts are concepts in use, ${ }^{6}$ i.e. have propositional content while the arrow of implication (203) being reducible to disjunction, contains no asymmetry. What is needed in matters of symmetry $v$ s. asymmetry is not an emancipation from an alleged

1 Mach [1917], p. 435. Cf. also Mach's comments on the conventional elements of the law of inertia mentioned above.

2 Mach [1933], p. 2 II. 'Mach [1917], p. 129.

1 Mach [1933], p. 218 and Mach [1922], 286 f., especially 286, lines $12 \mathrm{ff}$.

- Mach [1917], p. 443.

- $126 \mathrm{ff}$. and passim: Mach has a decidedly constructivist (in the sense of mathematical constructivism) attitude towards concepts. 
'conceptual' philosophy and its replacement by a Popperian propositionalism, 1 what is needed is 'more research' concerning natural processes.'

7 There are many other mistakes. Zahar: 'Mach thought . . . he could boil everything down to spatial measurements' (206). Mach: 'there is an unchangeable physical time object just as there is an unchangeable physical space object-the rigid body'. 3 Zahar: 'Elements . . . are the simplest component parts of sensations' (200-his emphasis); Mach: 'elements are sensations only insofar' as we consider their dependence on a particular complex of elements, vir. our body; 'they are simultaneously physical objects, vir. insofar as we consider other functional dependencies'. Disregarding the dependencies elements are therefore as much physical objects as they are sensations. ${ }^{6}$ Zahar's biggest mistake which makes manifest his ignorance concerning Mach's philosophy is to describe it as 'strictly positivistic' (198). ${ }^{6}$ Already the title of Mach's first major work should have given him pause. An author who writes an Analysis of sensations obviously does not take sensations as basic. And, indeed, Mach insists on an analysis of sensations including an examination of their dependence on physiological conditions, ${ }^{7}$ he regards results of such an analysis as "temporary' ${ }^{8}$ and sensation talk as involving a 'one sided theory' ${ }^{\prime}$; he asserts that introspection does not suffice as an instrument of analysis but must be combined with a physiological study'a, he points out that our ideas affect not only 'the development of experience' but 'enrich every ... f fact'", he objects to Mill's aversion to hypotheses which 'favours what has been found over what has still to be discovered'12, he encourages the researcher 'not to be too fearsome when introducing hypotheses. Quite the contrary, a little boldness in these matters furthers research's; ${ }_{-}^{\text {; he }}$ quotes with approval Priestley's observation that 'very lame and imperfect theories are sufficient to suggest useful experiments while serving to correct those theories and give birth to others more perfect. These then occasion farther experiments which bring us still nearer to the truth, and in this method of approximation we must be content to proceed ... '14; he describes himself as a

1 Zahar, like all good Popperians, ascribes even the most trite and useleas idea to Popper. In the case of propositionalism the origin is clear: it is Aristotle.

Mach [1933], p. 2 I9.

3 Mach [1917], p. 393.

4 Mach [1922], p. 13, my emphasis.

- Mach seems inclined to count some of Duhem's 'qualities' among the elements. $C f$. his introduction to the German translation of Duhem's main philosophical work, Ziel und Struktur der Physikalischen Theorien, Leipzig, 1908. But 'qualities', for Duhem, are physical primitives such as currents, charges and so on.

- Carnap [1 928], p. 87, notices with surprise that Mach's 'basis does not consist of events belonging to the perceiving subject' ('die nichteigenpsychische Basis') and point out that this feature 'constitutes a disturbing element in the total picture of his (Mach's) ideas'. Obviously he has formed a false conception of this picture-and he now notices difficulties. No such difficulties exist for the Popperian Zahar.

${ }^{2} C f$. Mach [18g6], p. 228.

Mach [1922], p. 24.

- 18.

10 Mach [1 896], p. 228.

12249.

11 Mach [1917], p. 245.

14240 f., my emphasis.

13247. 


\section{Paul Feyerabend}

'non-empiricist' or 'not-only-empiricist' and, considering his reconstruction scheme of science in terms of hypothetical elements (not sensations) he warns that 'there is no need to turn this passing point of view into a system for life whose slaves we then become . . ' T There is a great distance indeed between Mach's 'philosophy' ${ }^{3}$ and Zahar's rather unbelievable distortion of it. To ascribe such views to Mach shows not only an astonishing ignorance of relevant historical material; to assume that a scientist-philosopher and social critic of Mach's calibre ${ }^{4}$ should in the end have come up with such a sophomoric theory shows in addition an enormous lack of imagination and historical understanding. ${ }^{5}$

8 There is, then, no conflict between Mach's philosophy and the (genesis of the) special theory of relativity. But is there a positive relation? Are there elements in Einstein's early research that show a similarity to Mach's philosophy and may therefore be regarded as evidence of Machian influences? On the other hand-what are we to make of Mach's criticism of relativity? I shall now give some very tentative answers to these questions.

To explain Mach's criticism I draw attention to two passages contained in a longer quotation from Mach by Zahar (197). These passages both refute Zahar and also point to an answer rather different from Zahar's. The fact that Zahar quotes them and yet continues on his own line of attack shows to what an extent Popperian mythology is capable of blinding its followers.

Mach discredits relativity because he finds it 'growing more and more dogmatical' (first reason) and because of 'particular reasons', 'based on the physiology of the senses, the theoretical ideas and, above all, the conceptions resulting from experiments' (second reason).

I connect the second reason with Mach's attempt to find a point of view that is not restricted to a particular subject such as physics, or psychology 'but can

1 Hugo Dingler [1924], p. 61, footnote. Cf. also notebooks, vol. ii, p. 16 from back (contained in Dingler's book) where Mach puts sensations in their place and wants to free science from their dominance: Mach criticised not only realism, but all one sided philosophies. Zahar refers to Dingler's book, but seems to have read only a tiny part of it.

2 Mach [1896], p. 226. One should compare this quotation with the Einstein quotations in section 9.

' Mach refused to regard his hints or 'aperfus' ([1922], p. 39) as a philosophy: 'I am a scientist, not a philosopher . . . and I think I am innocent of the fact that people have regarded me as an idealist, Berkeleyan, even a materialist.' Loc. cit. 'Above all there is no Machian philosophy' he writes in the introduction to his [1917] p. vii-'there is, at most, a methodology of science and a psychology of knowledge and like all scientific theories these things nust be regarded as preliminary and incomplete attempts' (my emphasis). There are many philosophers with whom Mach feels he has 'points of contact', Spinoza among them ([1922], p. 38). Note how much more dogmatic critical rationalists sound when pronouncing on their 'philosophy'.

4 'I don't think anyone ever gave me so strong an impression of pure intellectual genius. He apparently has read everything and thought about everything, and has an absolute simplicity of manner and winningness of smile when his face lights up, that are charming . . . William James about Ernst Mach, letter to his wife of 2 Nov. 1882 quoted from Joachim Thiele [1978], p. I69. Of course, it is difficult for a dweller in the slums of late twentieth century philosophy of science to guess what an intelligent man may or may not assume.

- Or else it shows that Popperians, being engulfed by the banality of their own 'philosophy' have completely lost their sense of perspective. 
be retained in all domains'. 1 Or, to express it differently, but still in agreement with Mach's intentions ${ }^{2}$ : he sets himself the task to find theories that cut across traditional boundaries such as the boundary between physics and psychology without being beset by the mind-body problem. What have 'experiments' got to do with the construction of such a theory ${ }^{3}$ In an earlier essay Mach comments that 'the mental field', i.e. the domain where thoughts, emotions etc. appear and disappear 'can never be fully explored by introspection. But introspection combined with physiological research which explores the physical connections can put this field clearly before us and only thereby make us acquainted with our inner being' :4 introspection does not suffice; it grasps only part of 'mental events'; their whole nature is revealed by introspection plus physiology. The partially physical character of the research leads to the expectation that our 'inner being' may without break merge into the physical world thus providing a unified account of 'mental' and 'physical' events and laws. A purely physical theory of space (or spacetime) does not fit into such a research programme. This is the "particular reason'.

Now despite this disadvantage the theory of relativity might still be welcome as a step in the right direction were it not for the fact that it has been 'growing more and more dogmatical' (first reason). Was this the case? Was there really an increase of dogmatism, or what Mach regarded as dogmatism, in physics, in connection with the theory of relativity? Not on Einstein's part but certainly on the part of Planck, Mach's arch enemy. ${ }^{6}$ Planck, after some wavering, defended a reality of the kind Mach and Boltzmann had rejected, he regarded relativity as a step towards this reality, made himself many contributions towards the development and extension of the theory ${ }^{7}$ and so furthered its dogmatic interpretation. I conjecture that this explains Mach's criticism and the harshness of it but it also shows that the criticism does not touch Einstein's achievements. It concerns only their misuse for dogmatic philosophical purposes. ${ }^{8}$

1 Mach [1922], p. 255.

2 Op cit., p. 26.

2 Note that Zahar cannot explain the role of experiments in Mach's objections: one does not need experiments to show that a theory is metaphysical.

4 Mach [1896], p. 228.

s There.are various hypotheses concerning the 'experiments'. Thus Herneck conjectures that Mach objected to the assumption of the constancy of $c$ and that the 'experiments' dealt mainly with these matters: D. K. Heller [1964], p. 142. According to Herneck, Philipp Frank gave Dingler part of the responsibility for Mach's attitude. (Physikalisde Blätter, xvii, (1961), p. 276). However the fact that Mach emphasised the need to combine psychological, physiological, physical as well as biological investigations both in his early and in his late writings and that he deplored a purely physical approach to the problem of space seems to favour my interpretation: relativity was $O K$ especially as it introduced the interdependence of spatial and temporal aspects but it did not go far enough and it became a hindrance to research if interpreted dogmatically, in the manner of Planck.

- $C f$. the rather acrimonious exchange between Mach and Planck, republished in Toulmin [1968]. Although the tone of learned exchange was at the time a little less vapid than it is today, this was the only polemic Mach ever published.

; $C f$. the account and the literature in Stanley Goldberg [1972].

- Similar remarks apply to Mach's rejection of atoms. First a little myth should be laid to rest. Stefan Meyer of the Institute for Radium Research at the University of Vienna reports and many writers have repeated that Mach, having been shown a spinthariscope 
9 Is Einstein's work influenced by Mach? I think it is. However the influence becomes clear only if one disregards technical details and looks at the wider picture. We then notice that Einstein strives for the most direct expression of phenomena: electric induction depends only on the relative motions of the systems concerned while the aether theories treat the effects of the motion of a magnet (relatively to the aether) differently from the effects of the motion of a closed electric circuit. ${ }^{1}$ Lorentz explains null resulss approximately and using a variety of rather doubtful hypotheses ${ }^{2}$ while Einstein regards them as basic facts. $^{3}$ In his investigations of the structure of radiation Einstein does not start from basic theory, as Planck did, but from uncomprehended but empirically adequate laws and develops their 'ontological' consequences. 'The key to his reasoning' writes Martin Klein on this procedure 'was his reversal of Planck's procedure. Instead of trying to derive the distribution law from some more fundamental starting point, he turned the argument around. Planck's law had the solid backing of experiment; why not assume its correctness and see what conclusion it implied as to the structure of radiation?' He plays 'theoretical pictures $^{\mathbf{5}}$ (his term-most likely taken from Boltzmann whom he read carefully ${ }^{6}$ ) off against each other to find their limits. ${ }^{7}$ Like Mach, Einstein is mainly interested in 'theories of principle', ${ }^{8}$ i.e. in theories which cover a wide variety of phenomena without assumptions about details of their constitution (this also

said 'jetzt glaube ich an die Atome', Sitsungsberichte der Oesterreichischen Akademie der Wissenschaften-Mathematisch-Naturwissenschaftliche Klasse, Abt 2a, Band I59, Heft I/2, 5. Heinz Post has pointed out that Mach was a kind person, that Meyer was very enthusiastic and rather deaf and that he most likely misunderstood the kind remarks Mach made in such a personally difficult situation. And who would think that Mach who had not been impressed by some very powerful arguments (Brownian motion, for example) should fall for such a flimsy exhibition? Secondly, Mach's objections were firmly grounded in some very real difficulties of the atomic theory which were often forgotten in view of apparent successes. Finally, the nineteenth century atom has indeed disappeared and has been replaced by a much more complex entity, constituted out of relations between well-defined measurements and no longer in conflict with Mach's ideas.

I 'On the electrodynamics of Moving Bodies' quoted from Einstein and others [1923] p. 37 .

2 $C f$. the articles by Lorentz in Einstein and others [1923].

"I have not been able to obtain for the equations referred to moving axes exactly the same form as for those which apply to a stationary system.' Lorentz [1952], p. 230.

2 'Einstein simply postulates what we have deduced, with some difficulty, and not altogether satisfactorily, from the fundamental equations of the electromagnetic field. By doing so, he may certainly take credit for making us see in the negative result of experiments like those of Michelson, Raleigh and Bruce, not a fortuitous compensation of opposing effects, but the manifestation of a general and fundamental principle.' Actually, Einstein did not 'make us see it' that way, for there was no explanation, he simply took this situation as his starting point: 'Wir wollen diese Vermurung zur Voraussetzung erheben'-Einstein and others [1923], p. 26. English translation op. cit., p. 38 .

4 Klein [1964], p. 9. Cf. also T. S. Kuhn [1978], I80 f.

${ }_{3} C f$. the first page of his paper on the photoelectric effect reprinted e.g. in ter Haar [1967], P. 91 .

- $C f$. the references in Seelig's biography.

7 Mach was well aware of the fact that different theories could cover some domains equally well. $C f$. also his remarks on analogues in science his [1917], p. $220 \mathrm{ff}$.

- Cf. the autobiographical notes in Schilpp (ed.) [1949], esp. p. 53. 
establishes a link with Duhem). Einstein's remarks on geometry are in perfect agreement with what is found in the relevant chapters of Erkenntris und Irrtum ${ }^{1}$ and in earlier writings. ${ }^{2}$ As regards method, Einstein emphasises the great difference between the work of the scientist and the work of the epistemologist (philosopher of science): 'The external conditions' he writes' 'which are set [for the scientist] by the facts of experience do not permit him to let himself to be too much restricted in the construction of his conceptual world, by the adherence to an epistemological system. He, therefore, must appear to the systematic epistemologist as a type of unscrupulous opportunist.' 'Yes, I may have started it' he tells Infeld about a new fashion in physics-'but I regarded these ideas as temporary. I never thought that others would take them so much more seriously than I did.' 4 Or, in a lighter mood: 'A good joke should not be repeated too often. ${ }^{5}$ Compare this with Mach's 'the schematisms of formal logic and also of inductive logic are not of much use, for the intellectual situations are never repeated in exactly the same way. But the examples of great scientists are very instructive . . $\therefore$ the already quoted passage 'there is no need to turn this passing point of vrew (i.e. Mach's own suggestions) into a system for life whose slaves we then become" ${ }^{7}$ as well as with Mach's modest and somewhat mocking attitude towards his own 'philosophy' ${ }^{\prime 8}$ and you will see that Einstein and, as a matter of fact, all creative scientists are much closer to Mach than to, say, Popper. Mach, Einstein, Bohr use philosophy as an instrument of research that guides research but is also transformed by it while philosophers pontificate on a process they do not understand and would not know how to change. Small wonder they want to persuade us that Mach's ideas are as vapid as their own.

University of California, Berkeley Eidgenössische Technische Hochschule, Zürich

\section{REFERENCES}

Boltzmann, L. [1905]: Populaere Schriften, Leipzig.

CAjori, F. (ed.) [1962]: Sir Isaac Newton's Mathematical Principles of Natural Philosophy and His System of the World, Berkeley: University of California Press.

Carnap, R. [1928]: Der Logische Aufban der Welt; all page references are to the reprint, Hamburg 1974.

CLARK, R. W. [1971]: Einstein. New York.

${ }^{1} C f$. ch. I of Einstein's [1922] with pp. 353 ff. of Mach [1917].

2 Cf. Mach [ 1 866], his set essay on the development of our ideas of space, esp. p. 232. Cf. also Mach's note concerning Minkowski's 'Raum und Zeit' in the new (19\%9) edition of 'Die Geschichte und die Wurzel des Satzes von der Erhaltund der Arbeit' with reference to the relevant chapters of [1917]: 'Space and time are not regarded as self contained entities but as forms of dependence of the phenomena. I therefore move towards the principle of relativity which is also asserted (festgehalten) in 'Mechanik' and 'Waermelehre'-p. 60.

'Schilpp (ed.) [1949], p. 683f.

1 Quoted from R. W. Clark [1971], p. 340.

Philipp Frank [1948], p. 261.

- Mach [1917], p. 200. The same applies of course to the various theories of rationality which are of no use to the scientist but only provide philosophers with material for endless quarrels. 'Die Wissenschaft ist kein Advokatenkunststueck' says Mach [I9I7] and he is certainly right.

7 Mach [1896], p. 226.

Mach [1922], p. 39. 


\title{
282 Paul Feyerabend
}

CURD, M. S. [1978]: Ludwig Boltzmann's Philosophy of Science.

Dingler, H. [1924]: Die Grundgedanken der Machschen Philosophie, Leipzig.

Einstein, A. [1922]: The Meaning of Relativity, Princeton.

EInstein, A. [1936]: 'Physics and Reality', Journal Frankl. Instit. 221; all page references to the reprint in Ideas and Opinions, New York, 1954.

Feyzrabend, P. K. [1978]: Science in a Free Society. London.

Frank, P. [1948]: Einstein, His Life and Times.

Goldberg, S. [1972]: 'Max Planck's Philosophy of Nature and his Elaboration of the Special Theory of Relativity', Historical Studies in the Physical Sciences, 3 Philadelphia.

KuHN, T. S. [1978]: Black-Body Theory and the Quantum Discontimuity.

Lorentz, H. A. [1952]: The Theory of Electrons. New York.

MACH, E. [1866]: Zeitschrift fir Philosophie und philosophische kritik.

МАCH, E. [1896]: Populaerwissenschaftliche Vorlesungen. Leipzig.

МАС̈, E. [1917]: Erkenntnis und Irrtum.

MACH, E. [1922]: Analyse der Empfindungen. Jena.

MACH, E. [1933]: Die Mechanik, gth Edition. Leipzig.

SchiLPP, P. A. (ed.) [1949]: Albert Einstein: Philosopher Scientist. New York.

Toulain, S. [1968]: Physical Relativity. Harper Torchbooks.

\section{ON THINGS AND CAUSES IN SPACETIME*}

\author{
Introduction \\ I Things in Spacetime \\ 2 Causes in Spacetime
}

\section{INTRODUCTION}

Graham Nerlich's admirable article 'What can geometry explain?' [1979] persuades me that we should take the General Theory of Relativity to have reduced 'gravitation to spacetime curvature' (p. 8I). I agree with Nerlich that spacetime is an entity, irreducible to the spatiotemporal relations between the things and events in it; and that the variable curvature of its geodesics, induced by the distribution of matter, explains geometrically what we see as acceleration caused by gravitational forces.

From these truths, however, Nerlich has drawn two further, false, conclusions. One is that we must give up 'the space and time language of enduring continuants' (p. 8I); the other is that a serious puzzle is generated by 'the possibility of causal intervention by us to change the gravitational field' (p. 82). I take these points in turn, since the first is the more important and less obvious of the two and, when it is dealt with, the second can be disposed of quite easily.

\section{THINGS IN SPACETIME}

I take it that by 'continuants' Nerlich means what have been called 'substances' as opposed to events. I shall call them 'things', and I take them to differ from temporally extended events in lacking temporal parts. The question then is why accepting General Relativity as Nerlich construes it should force us to deny the

* This note was written during my tenure of a Radcliffe Fellowship, for which I am indebted to the Radcliffe Trustees. 